\title{
ENSINO DE CIÊNCIAS E FORMAÇÃO PROFISSIONAL EM SAÚDE DE NÍVEL MÉDIO: REPRESENTAÇÕES SOCIAIS E VISÕES DE CIÊNCIA
}

\section{Science education and professional formation in health in High School: social representations and visions of science}

Jairo Dias de Freitas ${ }^{1}$

Silvia Barreiros dos Reis ${ }^{2}$

Resumo: A noção de causalidade e de ordem permeia o entendimento das questões da vida, mesmo em uma visão dogmática. Partindo deste pressuposto, é plausível estudar o que dá sentido nas justificativas que embasam uma visão dogmática da ciência e que comumente tratamos de cientificismo. Com base em uma triangulação metodológica, desenvolveu-se um estudo de cunho qualitativo a fim de se mapearem, através das representações sociais, os elementos que fundamentam uma visão dogmática da ciência, considerando, como hipótese alternativa, uma visão otimista. Trabalhando com alunos do primeiro ano de um curso profissionalizante de Ensino Médio em saúde, observamos a presença de certos elementos do discurso cientificista ancorados, sobretudo, na ideia da ciência como único conhecimento. Assim, faz-se premente a historicização do saber-fazer cientifico, a fim de se contextualizar a ciência como produção humana.

Palavras-chave: Cientificismo. Representação social. Ensino de ciências.

\begin{abstract}
The order and causality notions pervade the understanding of life matters even in a dogmatic perspective. That being so, it is plausible to study the justifications that make dogmatic view of science meaningful, often treated as scientism. Based on a methodological triangulation, it has been carried out a qualitative study in order to map the elements that support such perspective by means of social representations, considering as alternative hypothesis an optimistic vision of science. Working with first grade mid-level students of a technical course in Health, we could observe the existence of certain elements of scientist discourse based on the conception of science knowledge as unique. Therefore, it is fundamental to understand the history of scientific activity so as to contextualize science as human production.
\end{abstract}

Keywords: Scientism. Social representation. Science education.

\footnotetext{
${ }^{1}$ Licenciado em Física, doutor em Saúde Pública e Meio Ambiente. Professor pesquisador, Escola Politécnica de Saúde Joaquim Venâncio, Fundação Oswaldo Cruz. Rio de Janeiro, RJ, Brasil. <jairotek@fiocruz.br>

${ }^{2}$ Bacharel e licenciada em Ciências Sociais, mestre em História Comparada. Pesquisadora colaboradora, Departamento de Antropologia, Museu Nacional, Universidade Federal do Rio de Janeiro. Rio de Janeiro, RJ, Brasil.<s_breis@yahoo.com.br>

${ }^{1}$ Avenida Brasil, 4365

Manguinhos - Rio de Janeiro, RJ

21.040-900 
Freitas, J. D.; Reis, S. B.

\section{Introdução}

As questões que este trabalho procura desenvolver se inserem em um desafio maior, que é o de se pensar e construir práticas pedagógicas referentes ao ensino de ciências na formação profissional de nível médio em saúde. Dentro da complexidade do tema, a questão principal abordada é a das visões dos alunos a respeito da ciência. Vislumbramos dois motivos importantes para este aprofundamento: o primeiro, de caráter mais específico, relacionado à formação profissional, é reconhecer as formas que fundamentam as visões dos alunos a respeito da ciência. Este é o primeiro passo para uma relativização e uma mudança de postura em relação às certezas do conhecimento científico frente a outros saberes, importante para futuros trabalhadores do campo da nova saúde pública, na qual se preconiza a participação popular mais efetiva (BUSS, 2000).

O segundo motivo, mais geral, relaciona-se ao fato de que vivemos em um contexto onde se coloca a necessidade do reconhecimento de outros saberes, que não os denominados científicos, para o enfrentamento das questões atuais. Exemplo disso são certas questões da vida, as quais admitem uma abordagem de cunho científico na sua formulação, mas cuja solução, entretanto, extrapola o domínio deste campo (FUNTOWICZ, 2002, p. 18). Problemas como o do esgotamento dos recursos do ecossistema e do aumento da pobreza, entre outros, vêm colocando em xeque a forma atual de se lidar com as questões da vida. Dessa forma, o próprio status do conhecimento dominante, nesse caso entendido como a ciência moderna, deve ser compreendido.

As visões atuais sobre a ciência são o resultado de um conjunto de fatores. No campo educacional, vale lembrar que, historicamente, foi a partir de um disciplinamento interno de saberes, que "o Estado, através de instituições e agentes legitimadores [...] pôs em ação toda uma série de dispositivos com a finalidade de se apropriar dos saberes, de discipliná-los e de pô-los a seus serviços" (VARELA, 1995, p. 90). O saber que antes sofria uma coerção externa, cujos critérios de seleção se davam a partir de seu caráter moral, passa, a partir dos critérios de cientificidade, a ter uma coerção interna. Nesse caso, a autora evidencia quatro procedimentos que foram efetivados (FOUCALT apud VARELA, 1995, p. 90): a eliminação e desqualificação de saberes, normalização dos saberes, classificação hierárquica e centralização piramidal a fim de permitir o controle. Isso foi possível, em parte, pelo sucesso de previsão e controle que as ciências naturais alcançaram. Do mesmo modo, a tecnologia, entendida lato sensu como aplicação prática da ciência, reforçou uma imagem de ciência como verdade (BRAGA, 2000). Contribuindo, assim, para que se instituísse a organização em disciplinas como temos hoje.

É possível perceber que, hoje, a manutenção da ciência como critério organizador e legitimador tanto dos conteúdos escolares em particular quanto da vida em geral, se dá por diversos aspectos. Desses, nos interessa estudar como o conhecimento científico é reificado.

\section{Cientificismo e representações sociais}

A relação entre ciência, tecnologia e sociedade compreendida pelos professores de ciência pode dar importantes pistas. Auler e Delizoicov (2001, p. 18), a partir de estudo quali- 
tativo sobre formação de professores de ciências no que tange às interações entre ciênciatecnologia-sociedade, apontam, em resultado preliminar, que os professores tendem a reforçar uma postura mítica de ciência. Três posições a respeito da ciência patentes desta visão seriam o que os autores denominaram de: superioridade do modelo de decisões tecnológicas, perspectiva salvacionista da ciência e da tecnologia, e a do determinismo tecnológico. Um critério relevante para o fortalecimento destes mitos passa pela concepção de neutralidade da ciência e da tecnologia em relação à sociedade.

Tal discussão remete a uma das maneiras de legitimação da atividade científica denominada cientificismo. Duas das características dessa visão que nos interessam são: a crença no progresso e na evolução dos conhecimentos científicos, que propiciará, no futuro, a completa explicação e domínio da realidade (ideologia da ciência); e a crença de que a ciência é atemporal e a-histórica, sendo a explicação do mundo (mitologia da ciência) (CHAUÍ, 1996, p. 280). Estas duas visões combinadas reforçam uma ideia de neutralidade científica e a de uma (con)fusão entre ciência e técnica.

Entretanto, vale salientar a dificuldade em se diferenciar uma posição cientificista de uma posição otimista em relação à própria ciência. O fato de se ter esperança a respeito, por exemplo, de cura de doenças atualmente incuráveis ou achar possível uma reversão dos problemas ambientais através de soluções científicas e tecnológicas não significa ter uma visão cientificista. Consideramos uma visão otimista aquela que aposta na possibilidade do progresso do conhecimento científico, ou dito de outra forma, tem uma expectativa positiva do futuro da ciência em relação ao presente. Entretanto, este progresso não é inexorável. Ao se referir à ciência enquanto atividade, o otimista a enxerga enquanto uma produção humana como outras manifestações, e com características próprias. Há uma vinculação desta atividade com o conjunto da sociedade, e isto é evidenciado na medida em que se entende que as finalidades da ciência ultrapassam suas fronteiras e dizem respeito ao ser humano em geral. A sua posição de otimismo, por outro lado, não o impede de perceber pontos negativos na atividade científica e, até mesmo, suas limitações. Por meio das representações sociais, é possível aferir elementos de otimismo e de cientificismo que permeiam o imaginário social.

Segundo Moscovici (2008, p. 22-23), as representações sociais podem ser entendidas como "um corpo de proposições, metáforas, julgamentos de valor e crenças figurativas", caracterizados pelos grupos sociais nos quais são produzidas e reproduzidas. Assim, constituem mundos de opinião, nos quais ressaltam três dimensões: atitude, informação e campo de representação ou imagem. A partir da organização de conhecimento sobre um dado objeto, informação, é produzida uma imagem ou conteúdo, campo de representação, a qual orienta e focaliza a relação com tal objeto apropriado na representação social (SÁ, 1996, p. 31). Dessa forma, as representações sociais denotam a produção particular de significado e significação aos diferentes grupos que organizam e se apropriam dos elementos envolvidos.

Knowing 'who' produces these systems is less instructive than knowing 'why' they produce them. If, in other words, we are to grasp the meaning of the adjective of 'social', we would do better to emphasize the function to which it corresponds rather than the circumstances and entities that it reflects. This function is specific to it to the extent 
Freitas, J. D.; Reis, S. B.

that the representation contributes exclusively to the process that shape social behaviour and orient social communication. (MOSCOVICI, 2008, p. 29-30) ${ }^{3}$

Destarte, a produção das representações sociais é dinâmica, alimentada e realimentada, construída e reconstruída no cotidiano das relações sociais. Os elementos presentes no imaginário social diferem segundo o espaço de produção e significação dos mesmos, e, dentro deste, segundo a realização individual na apropriação e organização do discurso. Segundo Baccega (2000, p. 14-15):

[...] o sujeito é, portanto, um indivíduo social autônomo porém não independente. Ambos os aspectos - independência e autonomia - nos são dados sobretudo pela língua, a qual fundamenta a percepção e articulação do mundo. Desse modo, entendemos o subjetivo não como característica do individuo isolado, ficção romântica, mas como ponto de chegada, resultado dos condicionadores sociais - portanto, não independente - ao mesmo tempo que ponto de partida, capaz de novas elaborações no caminho do conhecimento - portanto autônomo.

Assim, o discurso individual é organizado mediante um instrumental coletivo, do qual seleciona elementos para codificar e decodificar o mundo a sua volta.

\section{Materiais e método}

Como introdução ao curso de física, em uma escola de formação profissional em saúde, a saber, a Escola Politécnica de Saúde Joaquim Venâncio (Fundação Oswaldo Cruz), utilizamos uma estratégia pedagógica que possibilita um primeiro debate a respeito da atividade científica e de sua finalidade, desde 1995 nesta escola (VIEIRA; FREITAS; ALVES, 2004), e desde a década de 1980 em outras escolas públicas do Rio de Janeiro (GUERRA et al., 1990). Propomos um debate acerca do que é a ciência, sua relação com a sociedade e o trabalho do cientista. Para iniciar o debate, propomos que cada aluno escolha uma das três questões apresentadas e faça um desenho alusivo à temática selecionada. Socializam-se, após isso, os desenhos e os motivos da escolha deste em grupos e, depois, com toda a sala. Ao final, abre-se o debate para algumas questões relevantes que surgem na apresentação. Apesar do pouco amadurecimento sobre o tema, em geral, as turmas participam bastante da atividade e colocam seus pontos de vista sem muitas reservas, como se esperaria em uma primeira aula. $\mathrm{O}$

\footnotetext{
${ }^{3}$ Saber 'quem' produz esses sistemas é menos instrutivo do que saber 'por que' eles são produzidos. Se, em outras palavras, buscamos compreender o significado do adjetivo 'social', faríamos melhor em enfatizar a função à qual corresponde em vez das circunstâncias e entidades que reflete. Essa função é específica na medida em que a representação contribui exclusivamente para o processo que molda o comportamento social e orienta a comunicação social. (Tradução nossa)
} 
objetivo dessa atividade é o de problematizar as visões que surgem a respeito da ciência sem, no entanto, procurar conclusão, uma vez que esta é a primeira de muitas aulas em que estas questões podem ser retomadas.

Destarte, tal dinâmica foi proposta a uma turma, do primeiro ano do Ensino Médio, com 35 alunos de 14 a 16 anos. No tocante ao gênero, a composição é de 62,7\% de meninas para $37,3 \%$ meninos. Em relação ao perfil socioeconômico, 18,6\% dos alunos vêm de famílias com renda inferior a dois salários-mínimos; $49,2 \%$ de dois a cinco salários- mínimos; $28,8 \%$ de cinco a vinte salários-mínimos, e 3,4\% acima de vinte salários-mínimos. Quanto à residência, 52,3\% vêm da Zona Norte; 5,1\% da Zona Sul; 27,1\% da Zona Oeste, e 15,3\% da Baixada Fluminense. A partir de um sistema de cotas para alunos de escolas públicas, metade da turma é composta por candidatos aprovados elegíveis dentro desse parâmetro (CAMPELLO et al., 2008).

De caráter qualitativo e apoiada neste conjunto de dinâmicas em sala de aula, a pesquisa foi composta de três etapas: elaboração do desenho, debate em grupos temáticos com apresentação para a turma e uma redação sobre o próprio desenho e o debate em sala (Figura 1).

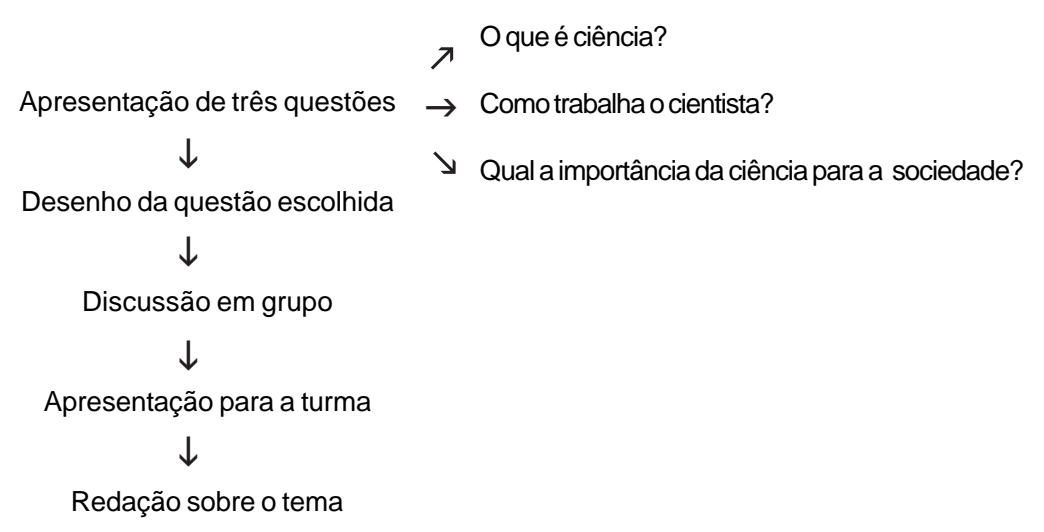

Figura 1. Atividade proposta em sala.

Fonte: Elaborado pelos autores.

$\mathrm{Na}$ primeira etapa, o aluno escolhe a pergunta a partir da qual desenvolverá o desenho. A questão o que é ciência é a mais aberta, uma vez que a segunda, como trabalha o cientista, oferece a possibilidade de representar uma prática, e não uma definição. Nela, buscamos, sobretudo, entrever a problemática do método, técnica e da falibilidade - e nestas, que ramo da ciência é representada. Na terceira questão, qual a importância da ciência para a sociedade, abrimos espaço para que representem a relação entre ciência e sociedade. Uma vez que esta pergunta possibilita a polarização valorativa entre ciência e sociedade, buscamos ver até que ponto a ciência é tratada como exterior à sociedade, sabendo que, dada a natureza da pergunta, somente no discurso é possível vislumbrar tal separação.

Uma vez concluída essa etapa, os alunos são reunidos em grupos de acordo com o tema escolhido, nos quais apresentam seus desenhos, conversam sobre a temática e escolhem um desenho que represente a ideia do grupo, para ser apresentado para a turma (também 
escolhendo um representante para tanto). Nesta etapa, então, temos dois debates, um dentro do grupo e outro suscitado na apresentação para a turma. A partir desta estratégia, os alunos traçam ligações entre os desenhos e os pontos levantados pelos colegas, aprofundando o debate no decorrer das apresentações. Não obstante, também é possível perceber as recorrências de certos elementos em seus discursos e a construção de um consenso da turma. Como exemplo, podemos citar a turma anterior à que descrevemos aqui, que, em todo o momento, voltava para a temática da ciência como conhecimento exterior, do qual possíveis alienígenas teriam melhor domínio, e a ciência como uma verdade que se tenta esconder ${ }^{4}$ do público.

$\mathrm{Na}$ terceira etapa, é pedido aos alunos que escrevam uma redação (sem mínimo ou máximo de linhas) sobre a temática que escolheram. As redações são analisadas segundo os elementos presentes e a relação entre eles, trabalhando, assim, tanto o conteúdo como o discurso. Da mesma forma, é realizado um confronto entre elementos presentes no desenho e elementos presentes na redação.

Como primeiro passo, os desenhos foram analisados separadamente, a partir de descrição de elementos representados. Uma vez criado o inventário de desenhos, iniciamos uma leitura preliminar das redações, mapeando o conteúdo segundo: tema, problema, tese, argumento e ideias secundárias. Para além da análise temática das redações, buscamos classificar os elementos presentes de acordo com categorias de análise, de forma a entendermos e mapearmos os elementos que fazem parte de uma visão cientificista.

Todavia, ao buscarmos nas redações o fundamento do cientificismo, propusemos uma hipótese alternativa de análise das redações, a do otimismo. Sendo assim, na análise dos elementos presentes, focamos em onze categorias, indicativas, no nosso entender, de traços cientificistas, e quatro categorias que denotam um otimismo, sem que isso seja considerado cientificismo (Quadro 1). Dessa forma, traçamos categorias cientificistas e seus contrapontos, os quais podem ser encontrados em maior ou menor grau, e em combinações diversas. Entendemos que o cientificismo pode ser percebido em gradação, uma vez que a presença de elementos caracterizados como cientificista não necessariamente denotam uma visão cientificista de modo absoluto, mas sim uma visão comprometida com ideais que se aproximam do cientificismo e podem levar a este em dado momento. Nesse viés, ao contrapormos com elementos caracterizados como parte de uma visão otimista, seria possível relativizar a presença de elementos cientificistas, entendendo o discurso para além da dicotomia cientificista versus não cientificista.

Assim, ao incorporarmos o otimismo como contraponto e hipótese alternativa, buscamos entrever quais facetas do cientificismo estão mais presentes, ao invés de classificarmos cada discurso apenas como cientificista e não cientificista.

\footnotetext{
${ }^{4}$ Nota-se, neste caso, a confusão entre o que é ciência e o que é tecnologia, ao descreverem, em grande parte, atributos da tecnologia ao falarem sobre ciência. Da mesma forma, foi recorrente a importância da divulgação. 
Ensino de Ciências e formação profissional ...

Quadro 1. Categorias de análise dos elementos presentes nas redações.

\begin{tabular}{|c|c|c|c|}
\hline \multicolumn{2}{|r|}{ Cientificismo } & \multicolumn{2}{|r|}{ Otimismo } \\
\hline 1 & Ciência como agente & & \\
\hline 2 & $\begin{array}{l}\text { Ciência como produtora de todos os benefícios e } \\
\text { mudanças na sociedade }\end{array}$ & A & $\begin{array}{l}\text { A ciência é apresentada como potencial de } \\
\text { melhora para a sociedade }\end{array}$ \\
\hline 3 & Ciência como entidade & \multirow[t]{2}{*}{ B } & \multirow{2}{*}{$\begin{array}{l}\text { Pontos negativos da atividade científica são } \\
\text { explicitados }\end{array}$} \\
\hline 4 & A atividade científica sem autores & & \\
\hline \multirow[t]{2}{*}{5} & \multirow{2}{*}{$\begin{array}{l}\text { Método científico como caminho inexorável do } \\
\text { conhecimento verdadeiro }\end{array}$} & C & O avanço científico não é inexorável \\
\hline & & D & A intenção da ciência está fora dela \\
\hline 6 & A intenção da ciência está nela mesma & & \\
\hline 7 & Ciência como único conhecimento & & \\
\hline 8 & Confusão entre ciência e técnica & & \\
\hline 9 & $\begin{array}{l}\text { Melhora linear e progressiva (da sociedade pela } \\
\text { ciência) }\end{array}$ & & \\
\hline 10 & Ciência como descoberta (e não construção) & & \\
\hline 11 & Cientista como herói & & \\
\hline
\end{tabular}

\section{Resultados e discussão}

Apenas um grupo pequeno de alunos escolheu a pergunta o que é ciência, formando, então, o único grupo que debateu e apresentou essa questão para a turma. Acompanhando os debates internos de cada grupo de alunos, foi externada a dificuldade de se definir ciência. Assim, a maioria optou pela segunda pergunta, como trabalha o cientista, formando três grupos de debate e apresentação. A terceira pergunta, qual a importância da ciência para a sociedade, foi debatida e apresentada por dois grupos de alunos. Essas duas questões foram relatadas como as mais fáceis de visualizar.

A apresentação dos grupos trouxe diversos elementos para o debate coletivo da turma, levando a uma interrupção na sequência de apresentação que levaria ao último grupo, sendo tecnologia o elemento em discussão e sua relação com a ciência. No Quadro 2, apresentamos os discursos elaborados na apresentação de cada grupo, resumidos em apontamentos, em ordem cronológica. Para potencializar o debate, os grupos foram reunidos em blocos de acordo com a questão escolhida, começando pela segunda pergunta e terminando pela terceira.

No findar da atividade, os desenhos foram recolhidos e, uma semana depois, as redações foram entregues. Dessa forma, os desenhos foram analisados, tendo em vista as categorias de análise para cientificismo e otimismo. Em seguida, as redações foram analisadas dentro dos mesmos parâmetros. Os resultados tabulados são fruto do cruzamento de ambos os meios, entendendo-os como duas formas de expressão com limites próprios que se complementam.

Assim, as questões 1 e 3 suscitaram respostas diversas, ao passo que a questão 2 se mostrou como veículo de respostas padronizadas, possibilitando a descrição, em sua maioria, apenas do método científico. Esperava-se obter nesta questão, em especial, ponderações sobre método e técnica. 
Freitas, J. D.; Reis, S. B.

Nas Tabelas 1 e 2, podemos aferir a presença das categorias de análise elencadas (Quadro 1, supracitado). Na última coluna, apresentamos os resultados combinados das questões 1 e 3 , desprezando a questão 2 .

Quadro 2. Apresentações dos grupos segundo o tema escolhido.

\begin{tabular}{|c|c|c|}
\hline $\begin{array}{l}\text { Grupos em ordem } \\
\text { de apresentação }\end{array}$ & Tema & $\begin{array}{l}\text { Apresentação para a turma } \\
\text { (discurso dos alunos) }\end{array}$ \\
\hline G1 & Como trabalha o cientista & $\begin{array}{l}\text { A partir da dúvida, o cientista pesquisa em textos, cria } \\
\text { uma hipótese e faz trabalho de campo para confirmá-la. } \\
\text { Se for bem-sucedido, cria uma teoria, que passa a ser } \\
\text { aceita e fica nos livros. Também, pode acontecer de não } \\
\text { obter a resposta, obter sucesso, a hipótese poderia estar } \\
\text { errada e ter de buscar outra. }\end{array}$ \\
\hline G2 & Como trabalha o cientista & $\begin{array}{l}\text { Pesquisa para um mundo melhor. Representação das } \\
\text { ciências naturais - física e química. }\end{array}$ \\
\hline G6 & Como trabalha o cientista & $\begin{array}{l}\text { O método como trabalha: } 1^{\circ} \text { observa o mundo como um } \\
\text { todo ao redor; } 2^{\circ} \text { formula hipóteses sobre o que está } \\
\text { estudando; busca soluções para resolver o problema. }\end{array}$ \\
\hline G3 & O que é ciência & $\begin{array}{l}\text { Ciência não tem resposta. É algo que tentamos achar } \\
\text { mas não encontramos nunca - respostas levam a outras } \\
\text { perguntas. "Alguém sabe quando os anéis de Saturno } \\
\text { vão parar de girar?" }\end{array}$ \\
\hline G4 & $\begin{array}{l}\text { Qual a importância da } \\
\text { ciência para a sociedade }\end{array}$ & $\begin{array}{l}\text { Uma cientista [representada]. Pesquisa para ajudar a } \\
\text { sociedade-como exemplo, vacinas. }\end{array}$ \\
\hline \multicolumn{2}{|c|}{$\begin{array}{l}\text { Debate suscitado pela turma antes da } \\
\text { apresentação do último grupo }\end{array}$} & $\begin{array}{l}\text { A própria ciência é tecnologia. Tecnologia em tudo para } \\
\text { avançar, melhorar e estudar. Um aluno disse que tudo } \\
\text { evolui com a informática, ao passo que outro respondeu } \\
\text { que não, que é a ciência que avança e produz a } \\
\text { informática. }\end{array}$ \\
\hline G5 & $\begin{array}{l}\text { Qual a importância da } \\
\text { ciência para a sociedade }\end{array}$ & $\begin{array}{l}\text { A ciência está no cotidiano - desenho de estruturas da } \\
\text { sociedade. Melhorar condições; também, pode estar no } \\
\text { mercado; com a tecnologia; sem ciência não há tecnologia } \\
\text { - ela está na embalagem dos alimentos, na casa, fábrica: } \\
\text { tudo envolve ciência. }\end{array}$ \\
\hline
\end{tabular}

Fonte: Elaborado pelos autores.

Tabela 1. Categorias relacionadas à visão cientificista.

\begin{tabular}{clrrr}
\hline & & N & 1-2-3 (\%) & $\mathbf{1 - 3}(\%)$ \\
\hline $\mathbf{1}$ & Ciência como agente & 3 & 14 & 25 \\
$\mathbf{2}$ & Ciência como produtora de todos os benefícios e mudanças na sociedade & 7 & 32 & 50 \\
$\mathbf{3}$ & Ciência como entidade & 6 & 27 & 50 \\
$\mathbf{4}$ & A atividade científica sem autores & 3 & 14 & 25 \\
$\mathbf{5}$ & Método científico como caminho inexorável do conhecimento verdadeiro & 0 & 0 & 0 \\
$\mathbf{6}$ & A intenção da ciência está nela mesma & 1 & 5 & 8 \\
$\mathbf{7}$ & Ciência como único conhecimento & 9 & 41 & 75 \\
$\mathbf{8}$ & Confusão entre ciência e técnica & 1 & 5 & 8 \\
$\mathbf{9}$ & Melhora linear e progressiva (da sociedade pela ciência) & 3 & 14 & 25 \\
$\mathbf{1 0}$ & Ciência como descoberta (e não construção) & 3 & 14 & 25 \\
$\mathbf{1 1}$ & Cientista como herói & 1 & 5 & 0
\end{tabular}

Fonte: Elaborado pelos autores 
Ensino de Ciências e formação profissional ...

Tabela 2. Categorias relacionadas à visão otimista.

\begin{tabular}{llrrr}
\hline & & N & 1-2-3 (\%) & 1-3 (\%) \\
\hline A & A ciência é apresentada como potencial de melhora para a sociedade & 6 & 27 & 41 \\
B & Pontos negativos da atividade científica são explicitados & 3 & 14 & 17 \\
C & O avanço científico não é inexorável & 1 & 5 & 8 \\
D & A intenção da ciência está fora dela & 8 & 36 & 16 \\
\hline
\end{tabular}

Fonte: Elaborado pelos autores

Do conjunto de desenhos e redações, 24 puderam ser analisados. Os demais alunos ou não entregaram o desenho ou a redação. Das redações analisadas, duas foram consideradas insuficientes para análise: uma por não conter desenvolvimento, apenas uma descrição em quatro linhas sobre a atividade desenvolvida em sala, e outra na qual o aluno fugiu do tema, caracterizando-se como resultado marginal.

O confronto entre desenho e redação possibilitou mapear estereótipos, isto é, representações ou conjunto de elementos presentes em diversos desenhos que, uma vez colocados em diálogo à respectiva redação, desvelaram a miríade de discursos que não necessariamente seriam apreendidos somente com o desenho. Como exemplo, podemos apresentar dois conjuntos de desenho-redação, cada um produzido por uma aluna.

No primeiro conjunto, no tocante ao desenho, encontramos, no centro, na parte superior, um hospital. Ainda no centro, abaixo, pessoa e bancada com frascos e potes - contendo legenda indicando que são remédios. À esquerda, seringa e folha sob lupa, sem ligação direta com o restante do desenho.

Assim, a importância da ciência para a sociedade, no primeiro conjunto, é a confecção de remédios, de recursos em benefício da sociedade. Dos elementos presentes, apenas a folha indica o processo envolvido ao caracterizar a questão da observação. Os demais elementos representam produtos finais da atividade científica.

Por outro lado, na redação, o discurso abrange muito mais que a produção de benefícios. Pondera, primeiramente, a definição de ciência, para assim abordar a relação entre ciência e sociedade. Por fim, considera a possibilidade de influências negativas por parte da produção científica, terminando com uma nota de otimismo:

Definir ciência é uma tarefa difícil, porém, podemos dizer que é uma das formas de conhecimento produzida pelo homem, como tentativa de entender e explicar racionalmente a natureza e os fenômenos que nela acontecem.

Através da ciência o homem busca formular leis e teorias que possam explicar o universo que o cerca. Este conhecimento, não pode ser considerado como verdade absoluta. Podemos verificar, ao longo da história, que verdades cientificas sofrem transformações, muitas vezes radicais em pequeno espaço de tempo.

A ciência se modifica a partir de imposições da própria sociedade, estando intimamente relacionados a transformação desta mesma sociedade.

Percebemos então, que a ciência pode trazer inúmeros benefícios para a sociedade, como: cura de doenças, remédios, enfim, vários produtos.

É claro que não podemos esquecer que existem efeitos maléficos. Muitas criações aconteceram e prejudicaram as pessoas, talvez intencionalmente ou não. De qualquer forma, ela traz beneficios e faz com que a sociedade cresça, evolua, possua mais conbecimento.

701

Ciência \& Educacão, v. 17, n. 3, p. 693-704, 2011 
No segundo conjunto, no desenho, encontramos, à esquerda, uma mulher com jaleco, sentada à mesa, segurando um tubo de ensaio e uma seringa. À direita, em recinto fechado, um homem com jaleco e estetoscópio, aplicando vacina em uma menina (que está chorando).

A importância da ciência para a sociedade, assim, está na atividade de pesquisa e produção de benefícios. $\mathrm{Na}$ representação de uma cientista trabalhando, podemos vislumbrar o momento de pesquisa, o qual é seguido, sequencialmente, no quadrante direito do desenho, pelo produto dessa atividade:

\begin{abstract}
A ciência é uma matemática não-exata que atua em um campo abrangente e complexo. A ciência ajuda a população de uma forma completa buscando criar a cura e a prevenção de doenças.

Hoje a sociedade está ligada diretamente a ciência, pois no campo científico são criados objetos de estudo relativos à ajudar a sociedade e tentar formular mais pensamentos.

Então, se a ciência é um meio complexo e infinito, ela é começo, o meio e o fim de tudo, pois todas as coisas existentes são ciências e esse campo de estudo rege o universo comprovando teorias, e acima de tudo buscando solucões em diversos campos da sociedade para melhorar cada vez. mais a vida da população.
\end{abstract}

Em ambos os conjuntos, os desenhos se assemelham tanto nos elementos escolhidos como na relação estabelecidas entre eles. Todavia, as redações diferem tanto nos elementos abordados quanto no discurso elaborado. Enquanto no primeiro conjunto é possível encontrar ponderações sobre os resultados da atividade do cientista para a sociedade, no segundo conjunto há apenas a apresentação dos benefícios. A definição de ciência também difere de tal forma que coloca os dois conjuntos em polos opostos no espectro dos conjuntos desenhoredação analisados: de uma ciência, com historicidade, como uma das formas de conhecimento do homem, a uma ciência como forma de conhecimento total e a-histórica.

Dessa forma, nos desenhos, podemos ver representações consagradas, que, de fato, comunicam com êxito a mensagem a ser transmitida. No entanto, tais representações, em geral, são apenas parte do repertório do aluno. Em outras turmas, pudemos averiguar um ou outro desenho no qual, por exemplo, os possíveis erros da atividade científica foram representados, seja pelo cientista chorando ou triste com algo que deu errado, ou por meio de legendas sobre o método, que tanto pode dar certo como errado.

Os resultados sintetizados nas tabelas 1 e 2 apontam para questões importantes a serem abordadas em um curso de ciências que objetiva um olhar crítico do fazer científico. Dos resultados, ressalta-se a tendência de grande parte da turma em caracterizar a ciência como único conbecimento. Em conjunto com outras duas características bastante recorrentes nas redações, a ciência como entidade e como produtora de todos os benefícios e mudanças na sociedade, reforçam uma visão cientificista da ciência. Por outro lado, parte expressiva da turma sugere um posicionamento otimista em relação ao conhecimento científico como possibilidade de progresso, mas não como certeza.

Assim, os resultados reforçam uma preocupação que se deve ter na formação de futuros profissionais de saúde. Como atuar numa sociedade múltipla e que diálogos são possíveis ao se entender a ciência como único conhecimento? Que mediações são possíveis? Se o conhecimento é entendido como exterior ao ator, que autonomia tem este frente às suas próprias condições de vida? 


\section{Considerações finais}

As representações sociais são fluidas, significadas e ressignificadas na dinâmica do processo contínuo de construção do imaginário social. Assim, tanto os elementos constituintes quanto a possibilidade de codificação e decodificação deles, isto é, a capacidade de entender e dar sentido a esses signos e relacioná-los, é particular ao meio no qual são produzidos. Como em uma dicotomia saussuriana, as representações sociais podem ser entendidas como elementos do aparato de um imaginário compartilhado por um grupo social, o qual é alimentado e realimentado pelos indivíduos, que, como a linguagem, são coletivas; ao passo que a realização destas, a apropriação e expressão desses elementos, é individual. Dessa forma, ao propormos a confecção de um desenho dentro de uma temática delimitada, o aluno organizará os elementos que fazem parte de seu imaginário e vivência para tentar cumprir a tarefa. Em se tratando de um desenho que foi requisitado e, assim, tem um destinatário conhecido e um espaço de realização definido, aquele que desenhará, buscará se comunicar dentro dessas variáveis. Os signos são entendidos em relação, na confecção do sentido.

Há, portanto, uma finalidade clara na produção de tal desenho, e a comunicação, a possibilidade de decodificação de seu desenho, é parte do objetivo final. $\mathrm{O}$ aluno, assim, adota estratégias para ter êxito na tarefa: se estimulado pela proposta, pode se esmerar ou extrapolar a proposta; também pode encará-la como um fardo e resolvê-la da maneira mais fácil e rápida possível; e há aqueles que ou não gostam de desenhar ou não sentem ter a habilidade necessária (nada impede que tal lamento seja parte, também, da estratégia daqueles que desejam se eximir da tarefa). Assim, é esperado que, nos desenhos, sejam encontradas concretizações passíveis de reconhecimento, tais como a representação de um cientista (geralmente, um homem de jaleco em um ambiente aparelhado com tubos de ensaio). No acesso e escolha dos elementos a serem utilizados, é esperado, também, o uso de estereótipos, seja para se comunicar seja para facilitar o próprio trabalho. A própria escolha do tema já aponta para duas possibilidades principais não mutuamente excludentes: facilidade de realização e interesse ou estímulo em uma temática específica.

Os resultados apontam alguns dos fundamentos que sustentam e legitimam a ciência. Uma mudança do ponto arquimediano, que sustenta, inclusive, uma dada representação a respeito da ciência, ocorre, no nosso entender, em se considerar a ciência como uma produção humana como tantas outras e de valor cultural, que caracteriza a sociedade atual. Um primeiro passo seria mostrar a ciência não como uma coisa que paira sobre a sociedade.

Assim, um esforço deve ser feito para deslocar a ciência do status de verdade absoluta. Isso possibilitaria o diálogo entre as diferentes formas de conhecimento, indispensável na formação em geral e na formação profissional em saúde. A historicização do saber fazer científico, em particular o desenvolvimento da ciência moderna, pode contribuir nesse sentido. Dessa forma, é possível mostrá-la como instrumento autoral fruto de uma conjuntura histórica determinada.

Considerando-se a formação de profissionais de saúde de nível médio, voltada para a promoção da saúde, seu campo de ação se configura no diálogo entre população e academia, saber popular e saber científico, sendo necessário um ensino de ciências preocupado em trazer ao debate seus próprios limites e possibilidades, incorporando, em sua prática, a problematização das formas de produção e legitimação de conhecimento. 
Freitas, J. D.; Reis, S. B.

\section{Referências}

AULER, D.; DELIZOICOV, D. Alfabetização científico-tecnológica para quê? Ensaio: Pesquisa em Educação em Ciências, Belo Horizonte, v. 3, n. 1, p. 17-29, 2001.

BACCEGA, M. A. Palavra e discurso. São Paulo: Ática, 2000.

BRAGA, M. A. A nova Paidéia: ciência e educação na construção da modernidade. Rio de Janeiro: E-papers, 2000. (Coleção Engenho \& Arte, v. 1).

BUSS, P. M. Promoção da saúde e qualidade de vida. Ciência e Saúde Coletiva, Rio de Janeiro, n. 5, n. 1, p. 163-178, 2000.

CAMPELlO, A. M. et al. Demanda e acesso aos cursos de nível médio em saúde da EPSJV/Fiocruz: estudo do processo seletivo 2007/2008. Rio de Janeiro, 2008. (Trabalho não publicado).

CHAUÍ, M. Convite à filosofia. São Paulo: Ática, 1996.

FREITAS, J.; REIS, S. B. Ensino de ciências e formação profissional em saúde de nível médio: no limiar entre o otimismo e o cientificismo. In: REIS, J. R. F.; RIBEIRO, C. G. (Org.). Temas de ensino médio: política, ciência e cultura. Rio de Janeiro: EPSJV, 2010. p. 61-71.

FUNTOWICZ, S. Ciência, complejidad y incertidumbre en los problemas ambientales: la perspectiva de la ciência posnormal. In: PORTO, M. F. S.; FREITAS, C. M. (Orgs.). Problemas ambientais e vulnerabilidade: abordagens integradoras para o campo da saúde pública. Rio de Janeiro: Fiocruz, 2002. p. 11-21.

GUERRA, A. et al. Representações sobre ciências e suas implicações para o ensino de Física. Caderno Catarinense de Ensino de Física, Florianópolis, v. 7, n. 2, p. 120-121, 1990.

MATTEWS, M. R. História, filosofia e ensino de ciências: a tendência atual de reaproximação. Caderno Catarinense de Ensino de Física, Florianópolis, v. 12, n. 3, p. 164-214, 1995.

MOSCOVICI, S. Psychoanalysis: its image and its public. Cambridge: Polity Press, 2008.

SÁ, C. P. Núcleo central das representações sociais. Petrópolis: Vozes, 1996.

VARELA, J. O estatuto do saber pedagógico. In: SILVA, T.T. (Org.). O sujeito da educação: estudos foucaultianos. Petrópolis: Vozes, 1995. p. 85-96.

VIEIRA, C. R. B.; FREITAS, J.; ALVES, N. G. Construindo uma área de ensino: a experiência das ciências naturais. In: ESCOLA POLITÉCNICA DE SAÚDE JOAQUIM VENÂNCIO (Org.). Temas de Ensino Médio: trilhas da identidade. Rio de Janeiro: Fiocruz; EPSJV, 2004. p. 184-194.

Artigo recebido em 02/08/2010. Aceito em 17/12/2010.

704

Ciência $\mathscr{E}^{2}$ Educacão, v. 17, n. 3, p. 693-704, 2011 